\title{
Analysis characteristics determination of electrohydraulic control system operation to reduce the operation time of a powered roof support
}

\author{
Dawid Szurgacz, ${ }^{1, *}$ \\ ${ }^{1}$ Center of Hydraulics DOH Ltd, 147 Konstytucji St., 41-906 Bytom, Poland
}

\begin{abstract}
The article discusses basic functions of a powered roof support in a longwall unit. The support function is to provide safety by protecting mine workings against uncontrolled falling of rocks. The subject of the research includes the measures to shorten the time of roof support shifting. The roof support is adapted to transfer, in hazard conditions of rock mass tremors, dynamic loads caused by mining exploitation. The article presents preliminary research results on the time reduction of the unit advance to increase the extraction process and thus reduce operating costs. Conducted stand tests showed the ability to increase the flow for 3/2-way valve cartridges. The level of fluid flowing through the cartridges is adequate to control individual actuators.
\end{abstract}

\section{Introduction}

Modern powered roof supports are extremely complex and require the most technically advanced solutions and tests concerning parameters of friction joints [1-4]. The research concerning the selection of the roof support which parameters would be suitable for given mining and geological conditions does not include the control system based on electrohydraulics [5-7]. At the same time it is necessary to pay particular attention to the reliability in terms of power supply, so that the individual elements of the longwall complex function properly $[8,9]$. The electrohydraulic control system for powered roof supports has a number of advantages and positive characteristics [10]. The research showed that a longwall equipped with the electrohydraulic control system has a greater level of safety than the longwall without such system $[11,12]$. Even if the capabilities of the automatization of the system are not fully used, the system is a valuable tool supporting top productive results. Such control system, however, has to be set and configured in a way that allows a steady shift from manual control to fully automated control.

The tests carried out in the past of the section advance time showed that the manual shift time was about 22 seconds, while the best result ever achieved with electrohydraulic control has been about 12 seconds [11-14]. The use of the electrohydraulic control for the implementation of the powered roof support involves also the exploitation of the longwall

"Corresponding author: dawidszurgacz@doh.com.pl 
without the participation of people. This solution mainly used in intact rock conditions $[15$, $16]$.

The article discusses basic functions of a powered roof support in a longwall unit. The subject of the research includes the measures to shorten the time of roof support shifting. Due to the specific nature of the process of coal mining, the powered roof support performs the function of the wall advance as safety function, protecting mine workings against uncontrolled falling of rocks. In order to introduce an innovative electrohydraulic control system for the powered roof support it is required to conduct an analysis and tests aimed at optimization of working parameters of the unit. The article presents preliminary research results on the time reduction of the unit advance to increase the extraction process and thus reduce operating costs. Conducted stand tests showed the ability to increase the flow for $3 / 2$-way valve cartridges. The level of fluid flowing through the cartridges is adequate to control individual actuators.

\section{State of the art}

A powered roof support as an element of a longwall complex is set by means of legs placed between a canopy and base. The lemniscate mechanism is used to mount the gob shield to the base. The structure of the longwall roof support during its operation takes over loads in the form of roof rocks and moves it to the floor. The stringer transfers the load from the roof to the floor [3].

The powered roof support unit consists of a canopy (1), legs (2), a lemiscate mechanism (3), a shifter with a beam connected to the stringers (4), a front wall shield, a cross-bar support, a gob shield (5). The stringer is the base of the support unit on which the hydraulic legs are set. The canopy is tightened against the roof with legs. The canopy supports the roof, while the gob shield protects it from caving. The force supporting the roof is generated by the pressure of the liquid in the space under the piston of the legs. The space under or over the piston of the hydraulic cylinder must be protected against overloads by a yield valve. Support unit's shifter, connected cylinder with a shifter and piston rod with a conveyor [17].
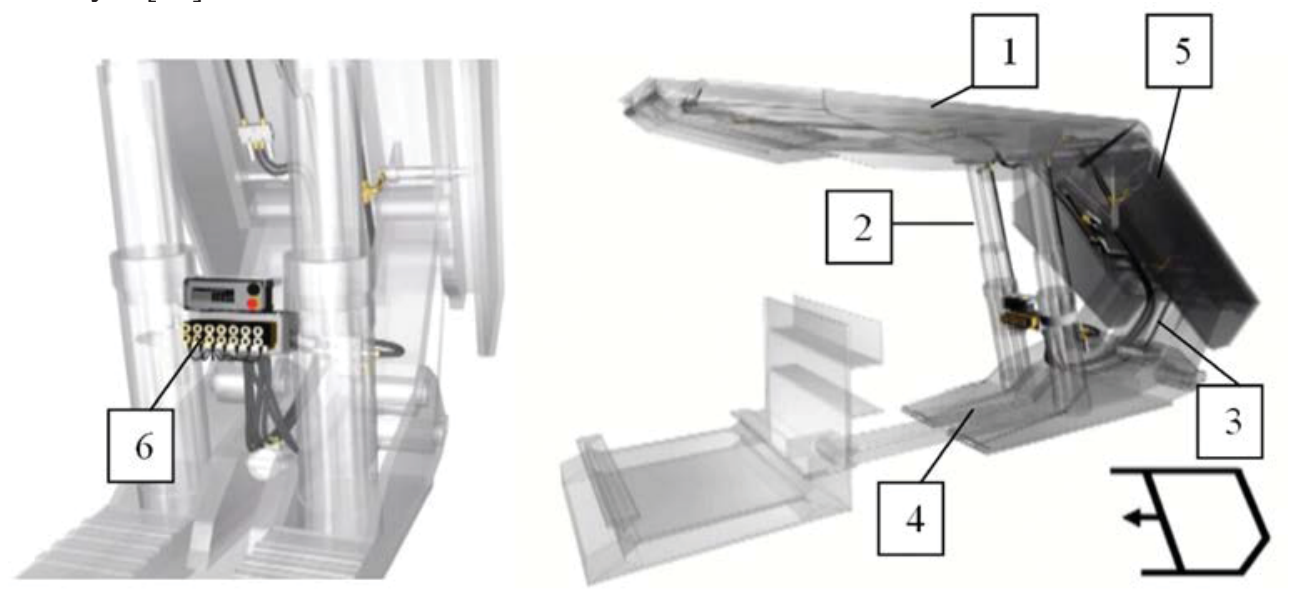

Fig. 1. Powered roof support unit.

The entire control cycle of the powered roof support unit begins with caving in. When the roof support moves, the piston rod is compressed and the sliding beam is stretched. Moving action of the conveyor causes the pressure to flow into the space under the piston, 
and as a result, the conveyor moves, while the fluid's pressure in the space over the piston causes tightening of the support unit against the conveyor. The moving unit must be caved in, the fluid pressure in the space under the piston of its legs must be reduced to the minimum. All functions are controlled by the control system (6). Each hydraulic cylinder is controlled with a control system consisting of a hydraulic block connected to it by hydraulic hoses. Roof support's hydraulic cylinders with the control block and the power source form the whole unit [17].

\section{Research analysis of the electrohydraulic system}

The research carried out for many years [10] shows the average recorded advance time of the powered roof support unit of about 12 seconds in the electro-control mode. For comparison, the manual unit advance times recorded were about 22 seconds. Recorded pressure measurement results for stressed legs generated by the roof and floor in the actual operation of the support. The analysis of the charts from the conducted tests of the pressure distribution in a leg allows to diagnose the technical condition and damage of the support hydraulics of the longwall support. Monitoring the pressure in the space under the piston of the legs and the operation of the pressure limiting valves allowed the study focused on the reduction of time of the unit movement to 9 seconds. The tests began with $3 / 2$-way valve cartridge measurement to examine its operability, resulting in a reduction in unit advance time.

The tests were carried using a testing bench that allows the development, commission and modification of the software, and to create virtual drivers. Moreover, it is possible to carry out measurements of the energy required to control selected types of solenoid valves that initiate chosen machine functions. Software of the test stand was created based on LabView application and allows conducting tests of control elements and parameters visualization and their operation. It is also possible to modify the functionality of the test stand, depending on ongoing research. The initial testing included the electrohydraulic part of the powered support control system, consisting of solenoid valves each comprising 4/3way control valves. A built-in set of 3/2-way valve cartridges DN12 or DN19 is responsible for the execution of tasks. The 4/3-way control valves receive a mechanical impulse generated by the dual electromagnet, and as a result they clip the 3/2-way valve cartridges, through which a suitable amount of fluid flows to control the individual actuators. Figure 2 shows the electrohydraulic part of the control system. 


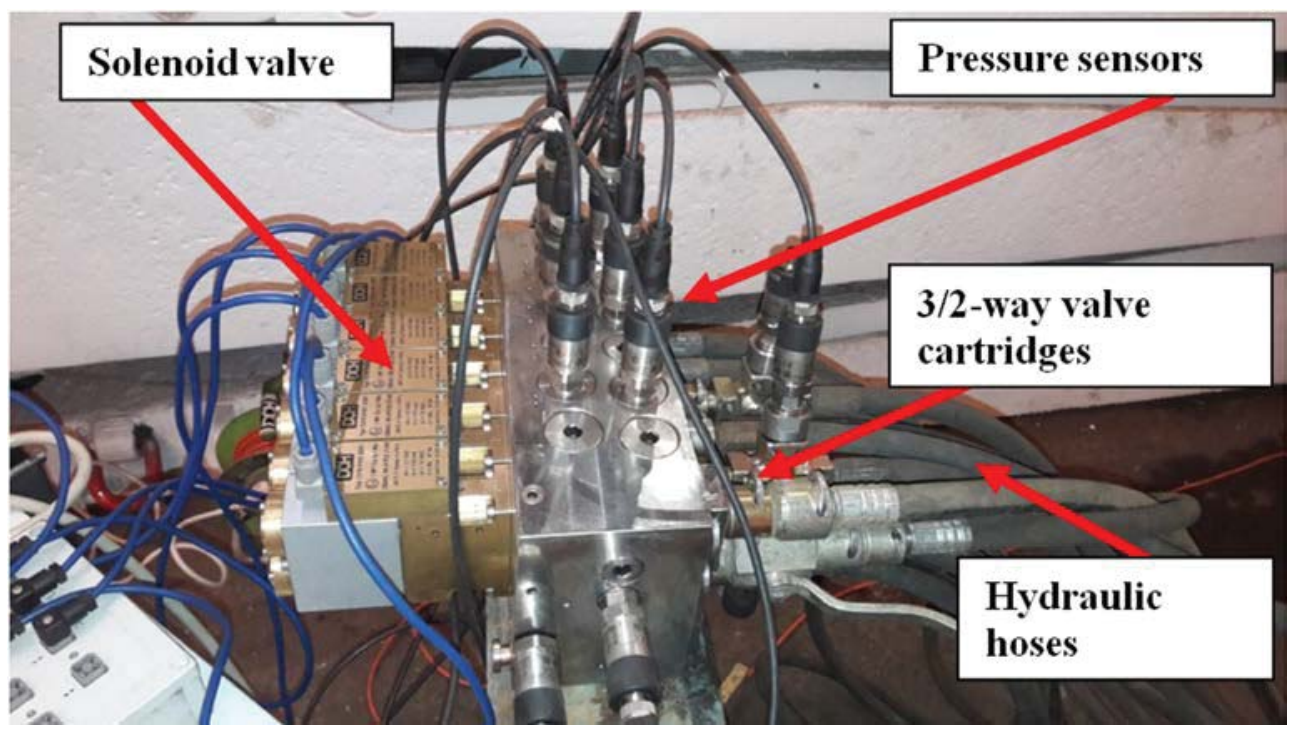

Fig. 2. Subject model of the roof support electrohydraulic control system.

The study included measurements of 3/2-way valve cartridges through which flows the fluid to control the valves of individual actuators. A set of pressure sensors and pressure gauges enables continuous monitoring of the pressure in the elements responsible for execution of tasks.

Preliminary studies on the reduction of unit advance time during the mining were carried out to examine the potential of way valve cartridges. Measurement of pressure values included 3/2-way valve cartridges for DN 10, DN 12 and DN 19, which performs an actuator function. The level of fluid flowing through the cartridges is adequate to control individual actuators. The tests included 18 measurements (as shown in the figures below) for different pressure values and DN values, as shown in Table 1.

The diagram shown in Figure 3 shows the performance characteristics for time waveforms the impacting on 3/2-way valve cartridges. The time waveforms obtained for different pressure values are shown in Table 1. Determined values for different pressures allowed for optimal timing characteristics.

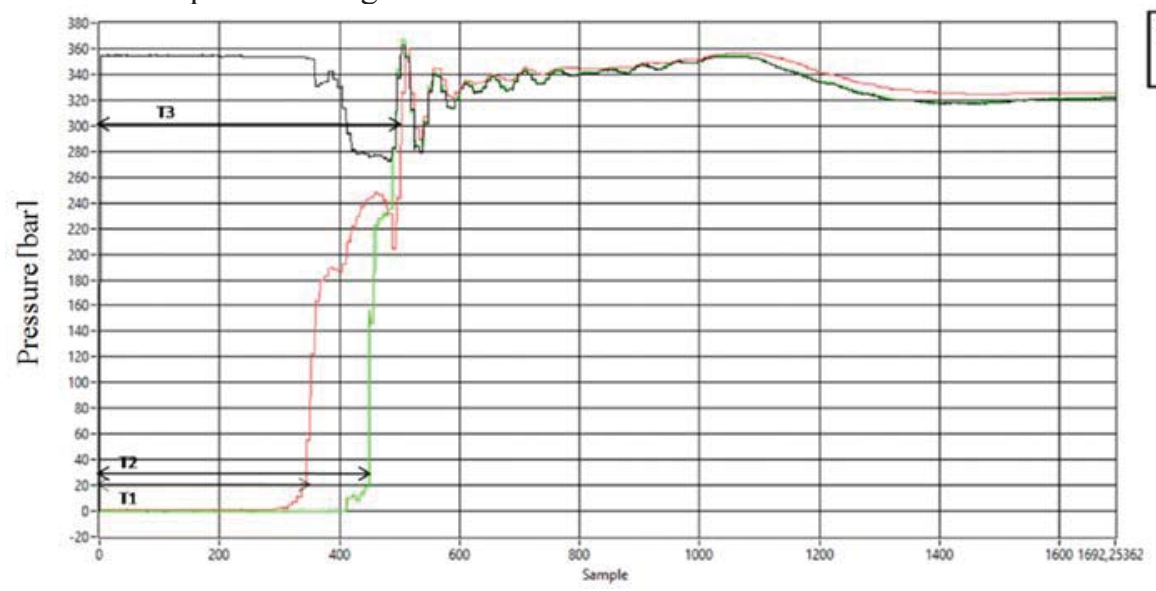

Fig. 3. Setting the response time for determining the characteristics of time waveforms. 
Table 1. Results of response time measurements for determining time waveform characteristics.

\begin{tabular}{|c|c|c|c|c|c|c|c|c|}
\hline Measur. & $\begin{array}{c}\text { Pressure } \\
\text { for T1 }\end{array}$ & $\begin{array}{c}\text { Pressure } \\
\text { for T2 }\end{array}$ & $\begin{array}{c}\text { Pressure } \\
\text { for T3 }\end{array}$ & $\begin{array}{c}\text { Pressure } \\
\text { for T1-T2 }\end{array}$ & $\begin{array}{c}\text { T1 } \\
\text { ms }\end{array}$ & $\begin{array}{c}\text { T2 } \\
\text { ms }\end{array}$ & $\begin{array}{c}\text { T3 } \\
\text { ms }\end{array}$ & T2-T1 \\
\hline 1 & 335 & 450 & 507 & 115 & 33.5 & 45 & 50.7 & 11.5 \\
\hline 2 & 336 & 492 & 528 & 127 & 33.5 & 49.2 & 52.8 & 12.7 \\
\hline 3 & 438 & 487 & 700 & 49 & 43.8 & 48.7 & 70 & 4.9 \\
\hline 4 & 412 & 460 & 696 & 48 & 41.2 & 46 & 69.6 & 4.8 \\
\hline 5 & 516 & 617 & 6,000 & 101 & 51.6 & 61.7 & 600 & 10.1 \\
\hline 6 & 536 & 620 & 6,000 & 84 & 53.6 & 62 & 600 & 8.4 \\
\hline 7 & 314 & 422 & 523 & 108 & 31.4 & 42.2 & 52.3 & 10.8 \\
\hline 8 & 350 & 492 & 541 & 142 & 35 & 49.2 & 54.1 & 14.2 \\
\hline 9 & 451 & 526 & 1,188 & 75 & 45.1 & 52.6 & 118.8 & 7.5 \\
\hline 10 & 406 & 467 & 1,286 & 61 & 40.6 & 46.7 & 128.6 & 6.1 \\
\hline 11 & 425 & 526 & 1,065 & 101 & 42.5 & 52.6 & 106.5 & 10.2 \\
\hline 12 & 470 & 577 & 1,035 & 107 & 47 & 57.7 & 103.5 & 10.7 \\
\hline 13 & 411 & 507 & $X$ & 96 & 41.1 & 50.7 & $X$ & 9.6 \\
\hline 14 & 458 & 470 & 6,956 & 112 & 35.8 & 47 & 695.6 & 11.2 \\
\hline 15 & 466 & 474 & $X$ & 108 & 36.6 & 47.4 & $X$ & 10.8 \\
\hline 16 & 359 & 453 & $X$ & 94 & 35.9 & 45.3 & $X$ & 9.4 \\
\hline 17 & 281 & 418 & 593 & 137 & 28.1 & 41.8 & 59.3 & 13.7 \\
\hline 18 & 320 & 450 & 642 & 130 & 32 & 45 & 64.2 & 13 \\
\hline
\end{tabular}

The characteristics shown below depend on the different pressure values in the 3/2-way valve cartridges for DN 10, DN 12 and DN 20, which perform an actuation function. The level of fluid flowing through the cartridges is adequate to control individual actuators. The tests were conducted for three DN sizes. They showed that with the increase in pressure flowing, its initial impulse impacts the value of the force transmitted by the control system of the roof support. The obtained characteristics were compared with the pressures of different DN. These tests presented in the graphs below were used to indicate the significant impact of a given DN for the same pressure values. Characteristics charts refer to the measurements in Table 1.

The analysis of pressure characteristics shown in the figures 4,5,6 below for different DNs indicates that the increase in the pressure in individual DN diameters can have a significant effect on the speed of the advance of the unit in the longwall system. Determining the right pressure and selecting the right $\mathrm{DN}$ diameter can reduce the time required for the proper operation of the powered roof support.

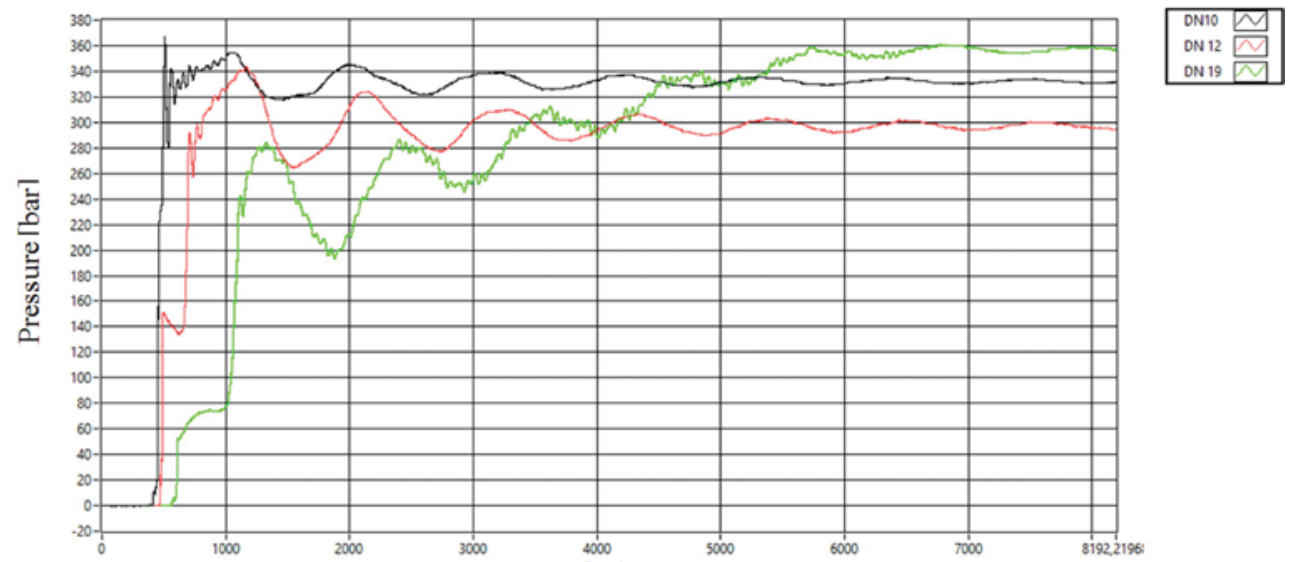

Fig. 4. 350 bar pressure characteristics. 

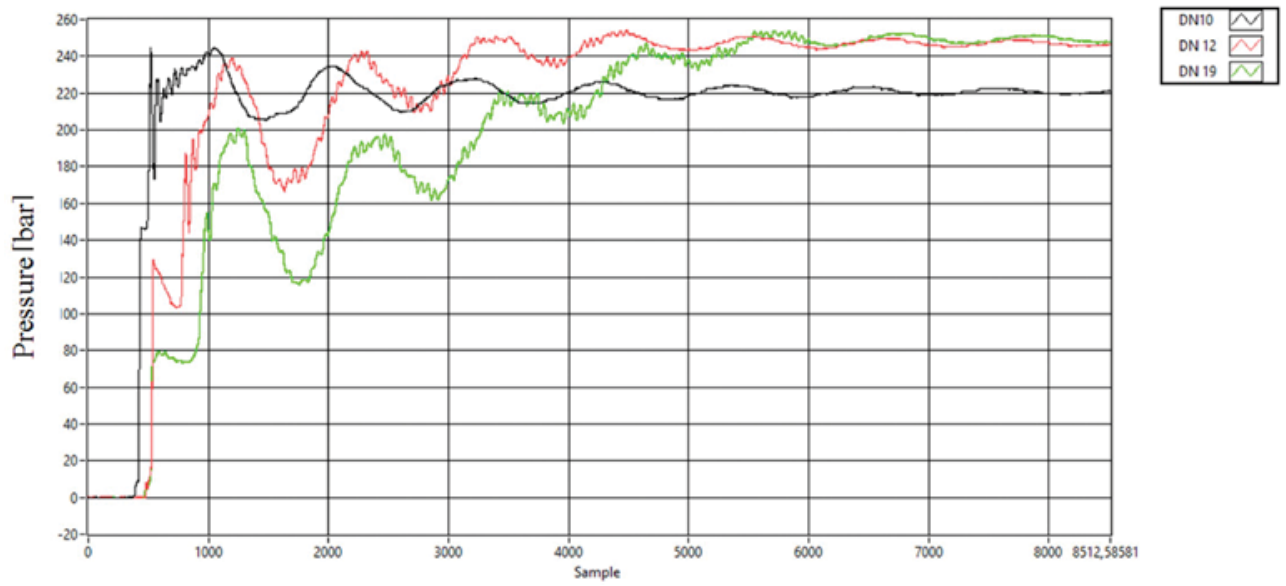

Fig. 5. 250 bar pressure characteristics.

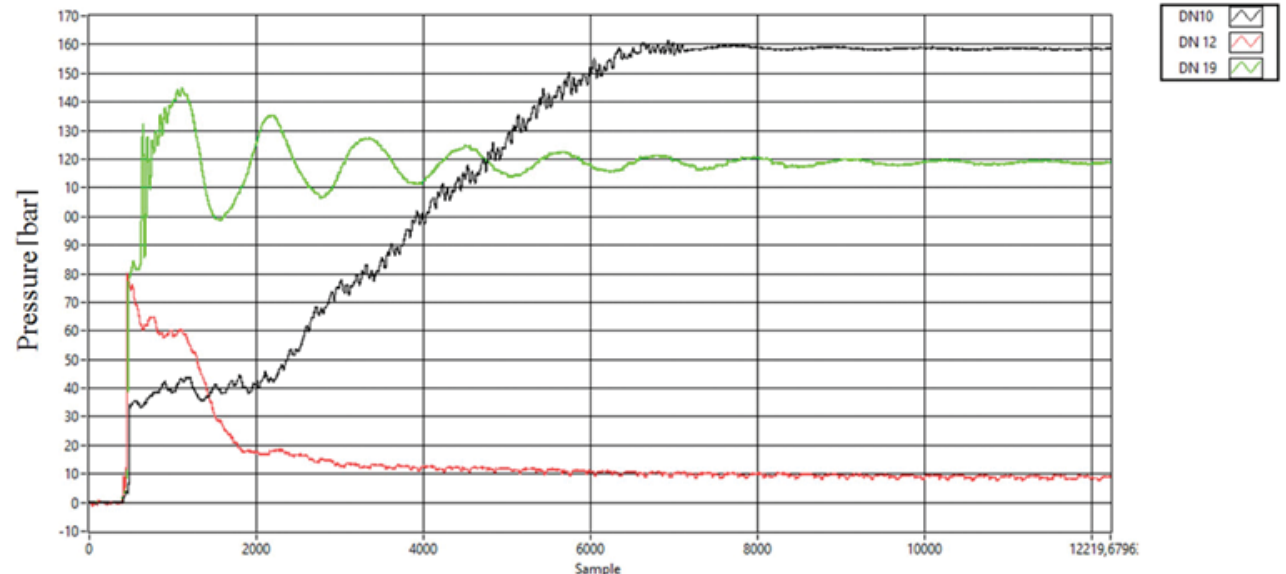

Fig. 6. 150 bar pressure characteristics.

\section{Conclusion}

Constantly worsening mining and geological conditions cause that the actions focused on costs optimization may affect work safety. The control system of the powered roof support, in spite of significant structural improvements and compliance with the principles of proper operation, does not protect the excavation sufficiently nor does it reduce the time required for the advance. The powered roof support has significant intrinsic value compared to other machines and equipment in which the mine is equipped. The longwall roof support is the basic protection of mining operation.

The comparison of the characteristics presented in the paper allow to conclude that the application of the DN19 diameter in the roof support's control block significantly increase the pressure value transmitted by the fluid flow. It can therefore be stated that the application of DN19 for a pressure of 350 bar for 3/2-way valve cartridges clearly indicates that a shorter adjustment time can be achieved. The research analysis made it possible to conclude that for higher pressures DN value must be increased. In the case of low pressure value, the 3/2-way valve cartridge is unable to transfer the energy required for the advancement of the section. Determining the maximum pressure and selecting the 
appropriate DN diameter will allow to obtain shorter times of unit advance during the mining operation.

The results obtained including the pressure increase for the optimal DN indicate that at its initial part the force needed to advance the section increases. The preliminary results of the study should be extended by developing an optimum electrohydraulic control of a powered roof support that will not only reduce the section advance time but will also improve safety.

The work was carried out within the project 'Innovative electrohydraulic control system for powered roof support' No. POIR.01.01.01-00-1129/15. Intelligent Development Operational Programme 2014-2020 carried out by the National Centre for Research and Development.

\section{References}

1. J. Brodny, Archives of Mining Sciences 56/2, 303-318 (2011)

2. J. Brodny, Archives of Mining Sciences 57/1, 209-227 (2012)

3. J. Brodny, Arch. Min. Sci., Vol. 55, No 4, 733-746 (2010)

4. M. Tutak, A. Dymark, T. Dzitkowski, MECHANIKA 2017, Proceedings of the 22nd International Scientific Conference, Kaunas 2017, 383-386 (2017)

5. S. Prusek, S. Rajwa, A. Walentek, W. Masny, $3^{\text {rd }}$ International Symposium on Mine Safety Science and Engineering, Paper No. 148, Montreal (2016)

6. S. Prusek, S. Rajwa, A. Wrana, A. Krzemień, International Journal of Mining, Reclamation and Environment 31/8 (2017)

7. S. Prusek, M. Płonka, A. Walentek, Arabian Journal of Geosciences 3/9 (2016)

8. A. Kozieł, D. Jasiulek, K. Stankiewicz, S. Bartoszek, Napędy i Sterowanie 2 (2012)

9. S. Mikuła, M. Wojtas, M. Skrabaka, M. Janik, P. Świecza, J. Kuska, K. Fitowski, Napędy i Sterowanie 1 (2013)

10. D. Szurgacz, Journal of Sustainable Mining 14/ 4, 157-163 (2015)

11. M. Janik, J. Kuska, P. Świeczak, M. Wojtas, K. Fitowski, Napędy i Sterowanie 7-8 (2011)

12. M. Janik, J. Kuska, P. Świeczak, M. Wojtas, K. Fitowski, Napędy i Sterowanie 9 (2012)

13. A. Kasprusz, S. Mikuła, M. Wojtas, Wiadomości Górnicze 5 (2013)

14. M. Schaeffer, Longwall Automation: State of the Art., Joy Corp., Mine Expo International, Las Vegas (2008)

15. J. Wen, Z. Lian, Web Information Systems and Mining Lecture Notes in Computer Science, 6987, 73-78 (2011)

16. M.X. Lu, M.F. Lv, J.G. Wang, M. Li, J. Zhao, Y.Y. Liu, Y. Zhao, J. Wang, Advanced Manufacturing Systems, ICMSE (2011)

17. J.B. Gwiazda. Tremor resistant mining roof support (in Polish), Wydawnictwo Śląsk, Katowice (1997) 